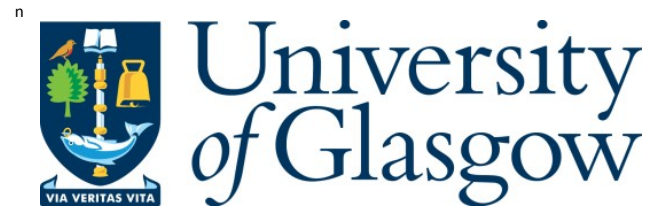

Kay, C., and A lexander, M . (2015) Diachronic and synchronic thesauruses. In:

Durkin, P. (ed.) The Oxford Handbook of Lexicography. Oxford University Press. ISBN 9780199691630

There may be differences between this version and the published version. Y ou are advised to consult the publisher's version if you wish to cite from it.

http://eprints.gla.ac.uk/70403/

Deposited on: 19 J anuary 2016

Enlighten - Research publications by members of the U niversity of Glasgow http://eprints.gla.ac.uk 


\section{Diachronic and Synchronic Thesauruses}

Christian K ay and M arc A lexander, University of Glasgow

\subsection{The Thesaurus}

A close sibling of the dictionary, thesauruses are those works of lexicographical reference which present lexical facts with semantic domains as their core organizational principle, rather than in alphabetical arrangement. Far from being a simple repositioning of existing dictionary entries in topical order, thesauruses are the

oldest recorded form of lexicographical work, and blend facts about the language with facts about the world in which the language is used. A s a result, the classification system at the heart of a thesaurus represents a synthesis of the conceptual vocabulary of a language, and of the relative place of each concept with regards to the wider conceptual system of which it is a part.

\subsubsection{At the End of the Alphabet}

W hile it may be natural for many present-day readers to consider a thesaurus as an accessory to a dictionary, given the dominance of the latter format's al phabetical order, this situation is mostly due to the dictionary system's ubiquity in recent years. By contrast, such was the historical dominance of the meaning-based ordering of information, the dictionary's alphabetical arrangement was so strikingly novel in its early publication history that Robert Cawdrey in his 1604 A Table Alphabeticall felt it necessary in his prefatory note "To the Reader" to explain this system, in a notoriously awkward passage: 
If thou be desirous (gentle R eader) rightly and readily to vnderstand, and to profit by this Table, and such like, then thou must learne the A Iphabet, to wit, the order of the Letters as they stand, perfecty without booke, and where euery Letter standeth: as $\mathrm{b}$ neere the beginning, $\mathrm{n}$ about the middest, and $\mathrm{t}$ toward the end. Nowe if the word, which thou art desirous to finde, begin with a then looke in the beginning of this Table, but if with v looke towards the end. A gaine, if thy word beginne with ca looke in the beginning of the letter $\mathrm{c}$ but if with cu then looke toward the end of that letter. And so of all the rest. \&c.

(Cawdrey 1970 [1604])

It is understandably difficult for a modern reader to comprehend the need to explain something as now ingrained as ordering items al phabetically, but Cawdrey's labour (along with earlier attempts such as that by Balbus in his 1286 Summa Grammaticalis, better known as the $C$ atholicon) can give a useful indication of the artificiality of such an arrangement.

The thematic and non-al phabetical thesaurus, by contrast, has a more immediately logical classificatory system, and a longer historical pedigree - although this logic comes at the expense of speed of access when a reader is searching for a particular lexical item. A s an al phabetical system is by far the most efficient option when a reader speedily requires a particular structured piece of data about a known and specific word, and as this situation is the prime usage case of a modern dictionary, the al phabet has held an almost unrivalled sway over lexicographical arrangement since Cawdrey's time, despite its disadvantages. A ccordingly, most thesauruses al so include an al phabetical index, either within their pages or as a separate volume, for ease of lookup. 
Nonetheless, given that alphabetical arrangement exists purely for efficiency of access, it is no exaggeration to say that this makes such an ordering intrinsically uninteresting. A lphabetical order tells a reader nothing about the word itself other than its opening configuration of letters, and leads to the alphabetical fragmentation of facts, detaching a dictionary so arranged from any possibility of linking order to meaning.

\subsection{The Structure of a Thesaurus}

By contrast to this al phabetical ordering, a thesaurus places meaning at the heart of its arrangement. Lexical facts are clustered with other, similar facts, arranged either on the grounds of semantic features, prototypicality effects, usage domains, or thematic harmony. Core to this principle is that, beyond a top-level arrangement devised for pragmatic reasons (see 24.2.1 below), thesauruses are arranged logically and systematically, and it should be apparent to a user how neighbouring entries in a thesaurus are related to each other.

While this system requires an alphabetical index for convenience of lookup, confident and frequent users of a thesaurus such as Roget's become familiar with the system of arrangement, and can find material with some ease. In many historical cases, as outlined below, such thesauruses structures exist either in tandem with, or derived from, an attempt to systematically categorize the world and all of human experience, with the assembly of lexical facts but one part of the overall endeavour. The converse is also true, with lexicographical works such as Roget's and the derived W ordN et being popular amongst computer scientists for categorisation systems. The general pattern of arrangement of a thesaurus is outlined below. 


\subsubsection{M acrostructure}

Scratch any thesaurus-maker and you are likely to find not only a lexicographer but al so someone ambitious to impose a degree of structure on the apparent disorder of the world around us. To some extent, this is inevitable, since a thesaurus has no predetermined order; one has to choose a starting point, and each category thereafter has to be related in some relatively transparent way to its fellows.

So while a thesaurus is primarily constructed from the bottom upwards, with words and concepts as their main building blocks, they require a high-level structure to be in place during its creation, splitting the world into major classes or categories, under which its other divisions can be placed. It is entirely possible to classify the semantic domain of Plants, say, or Emotions, in a wholly data-driven fashion, but it is much harder to then continually work upwards to an entirely empirical framework; decisions must be made, often on philosophical, psychological, or (more frequently) pragmatic grounds as to how to represent the large, abstract notions under which everyday life can be subsumed. These top-level classes often include such considerable concepts as Life, the U niverse, M atter, and so forth (see further Fischer 2004 for a comparative investigation of these structures). Such choices will often throw light on the intellectual climate and prevailing world-view(s) of the time when the thesaurus was produced. Hüllen (1999), for example, points out the shifting position of God in early classifications: initially usually at the beginning as the omnipotent creator, but increasingly towards the end as part of the social artefact of Religion, though occasionally somewhere in the middle.

Such major divisions form a thesaurus' macrostructure. They are frequently discussed in prefatory matter to a thesaurus (where such is given) or in the lexicographical literature, as their arrangement is necessarily arbitrary, although 
ideally logical. At the high level of abstraction these divisions operate, it is difficult to argue for the efficacy or naturalness of any of them, although pragmatic arguments can often be made for each.

The most famous macrostructure is that of Roget, which has 1000 categories split into six major classes, as explained in the discussion of Roget in 24.6 .2 below. Roget's macrostructure is shallowly hierarchical, having only a few layers of superordinate categories within which to place the concepts covered by the lexemes it collects, but it nonetheless illustrates the hierarchical framework which is necessary to unite a thesaurus' data-driven microstructure with the abstract macrostructure (the 'top-down' and 'bottom-up' parts of thesaurus-making). By contrast, Tom M cA rthur's Longman Lexicon of C ontemporary English (1981) is organized under fourteen major classes (themes), beginning with Life and Living Things, and includes definitions, citations, style labels, illustrations, and grammatical information (M cA rthur 1986: 147-50; 1998: 149-59).

The most complex thesaurus macrostructure is that of the $2009 \mathrm{Historical}$ Thesaurus of the 0 xford English Dictionary (HTOED), which was based on the contents of the second edition of the 0 xford English Dictionary (OED), in addition to other sources. The HTOED system begins with three major divisions - the physical world, the mental world, and the social world - and then proceeds from these into a hierarchical structure which can hold up to twelve nested levels of subcategorisation. This system is necessary to adequately organise the over three-quarters of a million lexemes which this work holds.

Finally, a thesaurus macrostructure can be as idiosyncratic as its compilers wish it to be - for example, P.R. Wilkinson's Thesaurus of Traditional English M etaphors bases its classification on a nursery jingle, meaning its highest-level 
divisions are Tinker, Tailor, Soldier, Sailor, Richman, [sic] Poorman, Beggarman, and Thief, with Wilkinson adding additional categories of At Home, At School, and At Play. This results in such startling subcategories such as G.2b "H ostile receptions with mud" and G.2d "Hostile receptions with dogs", contained under B eggarman (385-6)

\subsubsection{Microstructure}

W ithin a macrostructure, a thesaurus lumps or splits its contents to varying degrees of granularity, as do all other works of lexicography. A distinction can be drawn between those thesauruses which focus on distinctive microstructures, attempting to find classes with contents which are recognisably semantically discrete from all others in of similar meaning, and those which have cumulative microstructures, wherein the classes assembled contain many words with a relationship of similarity to each other, but are not finely distinguished in their meaning. A $n$ example of the former is the HTOED, with 236,000 categories for 797,000 words (an average of 3.4 words per category), while the latter is best exemplified by the 2002 edition of Roget's Thesaurus, which has 1,000 categories for "over 300,000 words" (approximately 300 words per category). In the case of a cumulative arrangement, the internal layout of a category list can be in order of frequency of use, alphabetical arrangement, parts of speech, or in a more impressionistic style which depends on the intuition of the compiler.

Each of these two structures has advantages and disadvantages. The primary disadvantage of a distinctive microstructure is the time and energy required to draw apart the subtleties of each word, arrange it into a separate category, and then decide where this category sits in relation to the enormous number of other categories which 
are necessitated by this system. For this reason, thesauruses in the distinctive camp often have a complex hierarchical structure to deal with the large number of categories it necessitates. The advantage of this style is that it gives precise and detailed information about each word in turn; similarly, the lack of this precision is often the disadvantage of cumulative microstructures, and tales abound of students misusing Roget by assuming any word in a Roget entry can function as a strict synonym for another. The comparative ease of constructing a cumulative thesaurus, al ongside its simpler structure for the user (a consideration mainly important in marketing rather than in actual usability), is the main advantage of this type of structure.

\subsection{Particular Types of Thesauruses}

The comparative rarity of thesauruses mean that they do not easily form a homogenous grouping. If the modern, synchronic thesaurus such as Roget is taken to be the stereotypical work, then thesauruses which differ from this straightforward model are easily found. They fall into the (non-exclusive) categories below.

\subsubsection{Historical Thesauruses}

If thesauruses are rare, then historical thesauruses are even rarer. In addition to the usual problems common to the field, historical lexicographers have to engage with issues such as scarcity of evidence, changing world views, and lack of appropriate encyclopaedic knowledge. The basic data usually come from historical dictionaries. It could be argued that creating thesauruses from dictionaries imposes another editorial layer betw een the lexicographer and the texts; on the other hand, there is little point in repeating work already done by other lexicographers. Problems can arise if the 
dictionaries disagree with one another, or the thesaurus-maker disagrees with the dictionary, or if, despite everyone's best efforts, the meaning of an older word is not fully known. Thus, in A Thesaurus of Old English (TOE), which classifies the A ngloSaxon vocabulary surviving in written form from the late seventh century A.D., the editors ended up with a category called simply "U nidentified plants". Plant names are notoriously difficult to interpret - there is no parallel category for the much more readily identifiable animals.

One solution to the problem of changing world-views is to allow the classification to emerge from the words rather than impose a classification upon them. This is the approach taken in Spevack's Shakespeare Thesaurus, which derives from an annotated database of Shakespeare's work. He writes that "... a pragmatic cycle of shuffling and filtering and reshuffling of the vocabulary has determined the classification: that is, the names were supplied after the groups began to take shape" (ix). This was also the procedure followed in TOE and the HTOED. All three also set up subcategories when the weight of vocabulary demanded it; to take Spevack's example, the lexicon suggested not only a category of ships, but also categories for various parts of ships, sailors, and navigation. Only when this stage has been reached can one begin to think about the role and importance of seafaring to the A ngloSaxons, Shakespeare and the Elizabethans, or English speakers over the centuries.

Such folk taxonomies, informed by what $\mathrm{Hallig}$ and von W artburg describe as "naïve realism", guided by "the intelligent average individual's view of the world, based on pre-scientific general concepts made available by language" (cited in Ullman 1962: 255), work well for thesauruses of languages remote from science such as B uck's Dictionary of Selected Synonyms in the Principal Indo-European Languages or TOE. Once expert scientific taxonomies become available, and part of 
at least some world-views, the classifier may want to take account of both, as John W ilkins did when he was confronted with John Ray's classifications of plants and animals and abandoned his original functional taxonomy of "plants for pleasure", "plants for nourishment" and "plants for medicinal purpose" (Hüllen 1999: 262-3). For HTOED, classifying tens of thousands of words across the entire 1300-year history of English, the expert taxonomy was often the best solution for major scientific sections, though folk categories like Domesticated A nimals or Cultivated Plants were included when justified by the data. ${ }^{i}$

W ithin the macrostructure, historical thesauruses which regard their data as belonging to a single period will usually display synonyms in al phabetically organized lists. Those with a diachronic spread, such as HTOED, will order lists chronologically, or will compromise by including some information about dates of use within an alphabetical list, as the Scots Thesaurus does. Headings will usually be in modern English, since it is unrealistic to expect the generality of users to be familiar with older English or Scots. By the same token, older or more obscure words may be omitted from the index. In TOE and HTOED, considerable care was expended on devising headings which would supply more information than is usual in thesauruses by a process of leading back from a specific to a general idea. Thus, in HTOED, one occurrence of the heading "W edding" leads back through numbered taxonomic stages to "Cake for special occasion" and thence to "Cake", "Dishes and prepared food", and eventually "Food" itself, enabling the reader to create something like a definition.

\subsubsection{Synonym Dictionaries}


W hile we have thus far discussed thesauruses as purely semantically arranged, there are also hybrid forms, which are sometimes called synonym dictionaries, containing small semantically-arranged lists of synonyms identified by a headword (eg some synonyms for pleasant), with thousands of those small packages then published in al phabetical order. These use what M cA rthur, discussing alphabetic reference books generally, describes as the "line and blister" model, where the line represents the al phabet and "... each of the blisters represents a special group of synonyms that are best explained together, or a semantic field that should be kept reasonably unified, or a special subject that ought to be covered in depth in one place - despite the al phabet" (1986: 156).

These have the advantage of being somewhat quicker to access than a wholly semantically-arranged work, and are often the dominant sort of thesaurus found in schools, but they also require either extensive cross-referencing (thereby removing their advantage of speed) or to publish the same information many times (with the same list of synonyms for pleasant repeated with slight variations under the headwords enjoyable, congenial, and so on). They include many works with "thesaurus" in their titles, such as the Collins English Thesaurus or the 0 xford Paperback Thesaurus. This style of thesaurus, being a somewhat awkward compromise, al though useful for some users, is not discussed here in any detail. Their creation does, however, require a good deal of compromise in balancing the convenience of the al phabet against what we might describe as thematic creep back towards the notional structure of the thesaurus.

\subsubsection{L earner's Thesauruses}

Thesauruses for learners are popular in two main areas. 
The first is where language-teaching works use a thesaurus structure as an intuitive way of learning vocabulary in semantic groups, and large numbers of language-learning textbooks use this system, usually with visual accompaniments for younger readers. In this area, it can be difficult to distinguish the somewhat fuzzy boundary betw een vocabulary textbooks semantically arranged, which are rarely called 'thesauruses' by their compilers or users, and the thesaurus proper.

"Learner's thesauruses" can also be used to describe an adult-learner-focused thesaurus, which is a standard thesaurus of one of the types above which is annotated, in learner's dictionary style, with far more metalinguistic annotation and use examples than a traditional thesaurus has. One of the first of these was M cA rthur's 1981 Longman Lexicon (see 24.2.1 above), and in more recent years this style is represented by the 20080 xford Learner's Thesaurus, which provides synonyms and antonyms within an al phabetical list of headwords, al ongside usage notes, pronunciations, patterns and usage labels, collocation lists, disambiguation information, and diagrams of scalar synonyms, all with the aim of assisting a learner of English. This thesaurus can be seen as continuing the innovative tradition of learner's dictionaries in the latter half of the twentieth century.

\subsubsection{Domain Thesauruses}

The market also offers a handful of technical domain-focused thesauruses on subjects like A rt and A rchitecture, but even these are often synonym dictionaries in disguise. B eing limited to a single domain, where meanings are less controversial, expert taxonomies are often available, and polysemy is rarely a problem, they are relatively easy to compile and are often of little interest to the non-expert. 


\subsection{The Function of a Thesaurus}

There are a wide variety of uses which can be found for a thesaurus, in any of the three forms outlined above (distinctive-semantic, cumulative-semantic, and synonym dictionaries). A thesaurus can firstly act as what Haartman and J ames call an active dictionary, one which is "designed to help with encoding tasks, such as the production of a text" (1998:3). This is perhaps the most common use of a thesaurus as a general reference work, often to assist writers in finding either an alternative term to one they have al ready used, or a more fitting word for a concept than the one which immediately springs to their mind. Similarly, historical thesauruses can be used to give an air of authenticity to works of historical fiction, amongst others.

W ithin thesaurus categories, one can also find the range of expressions available to a speaker to encode a concept and thereby see those competing terms that a speaker chose not to use, thereby enabling a literary scholar or a political historian, for example, to discuss word choice by a particular speaker and analyse the subtleties of picking one expression over its opponents.

Similarly, in a comprehensive historical thesaurus, insights can be offered into both language and society. Often the size of a category and its level of detail will indicate the importance of an artefact or concept to a society. TOE, for example, is lexically rich in many aspects of warfare, such as weapons and warriors, showing their role in the literature of the time, or at least in what has come down to us. The chronologically-ordered HTOED can be used to pinpoint areas of lexical growth and decline, for example in technology, foodstuffs, and leisure activities in the modern period. It can also show relationships among words of similar meaning, as when substantial numbers of words of OE origin were displaced by French words after 1066 in domains such as Law and Religion. Sometimes semantic ordering can reveal 
connexions between words when there are long gaps in the record: OE becca "a pick or mattock" can be linked to OED beck in the same meaning, not recorded again until 1875. Those writing dictionary definitions can use a thesaurus to locate a word among its synonyms, which may have changed radically over history. Thus W el sh English gambo originally referred to a low, flat cart, but was subsequently extended to other rudimentary or makeshift forms of transport, including an old, dilapidated motor-car, which links it to the HTOED category listing such vehicles. The fact that such a category is al ready well-established may justify a mention of this meaning in the definition of gambo or even recognition of a separate sense. ${ }^{\text {ii }} \mathrm{W}$ ordlists may also throw light on sound symbolism. Examining the HTOED category for Harsh, discordant sounds, and the abstract category of Complaint, provides fairly convincing evidence for the link between the / $\mathrm{gr} /$ cluster and these concepts ( $\mathrm{K}$ ay forthcoming).

M uch can also be revealed by an in-depth study of a particular field. W ild, for example, traces the development of terminology for 'young person', 'child', and 'baby/infant' and notes how age is increasingly used as a classifier, as in toddler, preschooler, and teenager, suggesting "the increased attention paid to children as a section of society" (2010: 298). A lexander and Struan (forthcoming, 2013) discuss the HTOED's Civilization category, suggesting five separate metaphorical conceptions of those people discussed as being 'uncivilized' throughout the history of English (namely the categories of wildness, crudeness, foreign-speaking barbarity, incivility, and the state of being significantly Other).

A thesaurus al so encodes world views of its compilers. R oget's attitude towards women and sex is notoriously encapsulated in his thesaurus structure and categories, both in how he categorizes parts of the body and in what he omits (the later changes to Roget also map how attitudes differed in the latter twentieth century). 
Thesauruses can even be used to predict the future. One of the most original volumes of recent years is B urger's Wordtree, described on its title page as "A Transitive Cladistic for Solving Physical and Social problems. The dictionary that analyzes a quarter-million word-listings by their processes, branches them binarily to pinpoint the concepts, thus sequentially tracing causes to their effects, to produce a handbook of physical and social engineering". Having found existing dictionaries "overly humanistic", the editor turned to the language of technology, "an increasingly important part of the mapping of any culture seeking to control its environment".

Over a period of twenty-seven years, he collected transitive verbs, analyzed them into binary semantic primitives, and combined them to form a multiply cross-referenced hierarchy of lexical items, where each word is defined by a word from the level above, plus a differentiating component (Wordtree: 13-14). This is a book like no other, yet the comment "Each scientific revolution produces a somewhat different grammar and world-view" gives us a clear indication of the use of the thesaurus as an insight into both these revolutions and their associated world-view.

Finally, when a thesaurus is created on the basis of a complete and fixed corpus, as with TOE, a weal th of information is opened up about the nature of not only that language, but al so that corpus - the paucity of words in this thesaurus for terms of endearment between two people is not a reflection on the A nglo-Saxon peoples, but rather one on what writings we have of theirs that survive.

\subsection{C reating a Thesaurus}

Thesaurus creation differs relatively little from the creation of dictionaries in many regards: some raw data, either a corpus, a collection of citations, or another dictionary, is analysed in order to collect a series of lexical facts, the most important 
of which for a thesaurus are the word form and its meaning (often these are the only pieces of information included in a thesaurus). The main difference is in the arrangement stage, which in a dictionary is easily done using the al phabet, but in a thesaurus often takes up the bulk of the work. If a macrostructure is already in place, then the body of lexical items involved are then split into the major classes, and then the entirety of such classes are then analysed in turn. The most commonly-used system here is a simple one, involving arranging the large bulk of these words, often in the time-honoured lexicographical paper-slip format, into large groups, then taking each group in turn and creating smaller groups, then taking these smaller groups and categorising them yet more finely, and so on until the desired level of granularity is met. In practice, there is often a lot of cross-reference and cross-pollination of word senses across these working categories. Decisions are also necessarily pragmatic and focused on the data, which makes following a particular theoretical orientation often quite challenging - although it is a notable benefit of such work that it can provide empirical data which can feed into linguistic theories (such as prototype theory in cognitive semantics).

A thesaurus can also be created by adding semantic tags to an existing lexicographic database, as was done with the Scots Thesaurus, but in practice this requires a very particular set of skills to be done accurately out of semantic order, and adds another large field of practice to the work of hard-pressed lexicographers, particularly if it is being done as a dictionary is being compiled.

\subsection{A B rief $\mathrm{H}$ istory of Thesauruses}

A lthough alphabetically arranged dictionaries now dominate the market, thematically organized thesauruses have a much longer history in the annals of lexicography. ${ }^{\text {iii }}$ 
Hüllen (2009a: 27-28) notes that: "In classical antiquity, and even in the older Chinese, Sanskrit, and A rabic cultures, dictionary-making began with the compilation of lists, for which words were selected according to semantic principles". These lists might comprise terms for domains such as animals, plants, or family relationships, and were often intended as aids to understanding older texts, such as the Homeric epics. Their purpose was thus didactic, and as they developed they assumed the further purpose of imparting information about the world as well as the terminology needed to discuss it.

L atin texts with marginal or interlinear glosses in Old English (OE) survive from the eighth century A.D. onwards. Over time, these glosses were collected into wordlists, at first related to particular texts, then gathered into independent lists, sometimes al phabetical but often in thematic order. Their primary purpose, as in other parts of Europe, was the teaching of Latin. Favourite topics included the body and its parts, precious stones, medicinal herbs, and natural kinds such as animals, birds, fish, and plants. This practice continued during the M iddle English period (1150-1500 A.D.), with glosses al so in A nglo-N orman and Old French. Increasing attention was paid to social domains such as the church, civil society, arts and crafts, and the home.

In the fifteenth century, materials for learning vernacular European languages began to appear, stimulated by social changes such as the introduction of printing and increased literacy and mobility among the population. These materials often consisted of multilingual thematic lists, with words from up to eight languages appearing in parallel. English, however, was a low-prestige language at the time, and was rarely included (Hüllen 1999: 105). The R enaissance period al so saw the appearance of many new or translated works on technical subjects such as warfare, navigation and horticulture; some of these were accompanied by thematic glossaries. 


\subsubsection{Organising the world}

Stimulated by scientific discovery, interest in classification gained momentum during the seventeenth century, while increased contact with other languages as a result of trade and exploration led to a fascination with the idea of a universal language which might be understood by everyone. A $n$ early manifestation of these interests was J ohn Wilkins' An Essay towards a Real Character, and a Philosophical Language, published in 1668. This enterprise is based on the assumption that all people perceive the world in the same way, and will therefore be able to communicate common concepts to each other through a set of universal symbols which transcend the limitations of actual languages, thereby returning humankind to happier prelapsarian times. There is no space here to do justice to Wilkins' system, ${ }^{\text {iv }}$ which presents his universal notions in a structured taxonomy leading from broad general classes such as "vegetative species" to groups of synonyms for individual concepts such as "spending" and "keeping", listed where appropriate with their antonyms. Suffice it to say that, although he aimed beyond a thesaurus of English, W ilkins' work had a profound effect on the subsequent development of thesauruses, and especially on the work of Roget.

Between Wilkins' work and Roget's, there was very little interest in thesauruses. A ttention was rather focused on ever larger and more sophisticated al phabetical dictionaries. Such interest as there was in a quasi-onomasiological approach manifested itself in al phabetical dictionaries of synonyms, of which the best known are probably Hester Lynch Piozzi's British Synonymy (1794) and George Crabb's English Synonyms Explained (1816). Such books often had the purpose of 
improving stylistic choice through discussion of the nuances of semantically close words - another development of importance in Roget's work.

\subsubsection{R oget's Thesaurus of English Words and Phrases}

Roget's Thesaurus of English Words and Phrases must rank as one of the publishing successes of all time. W riting in 1970, E mblen claims that by then 20 million copies had been sold since the first edition in 1852 (E mblen 1970: 272). By the time of K endall's biography in 2008, that total had risen to 40 million (K endall 2008: 1). These figures include the six editions published by Longman between 1852 and 2002, and imprints from other publishers.

Peter M ark Roget lived from 1779-1869 and had a distinguished career as a doctor and scientist before returning after retirement in 1842 to his earlier interest in wordlists. In the Preface to the first edition, he reports that " ... I had, in the year 1805, completed a classed catalogue of words on a small scale, but on the same principle, and nearly the same form, as the Thesaurus now published" (Davidson 2002: xix). He goes on to say that he had found such lists "of much use to me in literary composition", thus asserting from the outset the main reason for his work's popularity: its usefulness as a resource for those searching for an appropriate word. His comment highlights the key difference between a thematic thesaurus and an al phabetical dictionary. A thesaurus is a productive, encoding device, proceeding from meaning to words expressing that meaning, whereas a dictionary is a receptive, decoding tool, moving from known word forms to their meanings.

In the Introduction which follows the Preface, R oget explains how he had arrived at a "system of classification of the ideas which are expressible by language ... arranging them under such classes and categories as reflection and experience had 
taught me would conduct the inquirer most readily and quickly to the object of his search" (Davidson 2002: xxiii). This results in six primary classes: 1. A bstract relations, including Existence, Quantity, Order, Number, Time; 2. Space, including Dimensions, Form, and M otion; 3. M atter, its Properties, and Perception through the five senses; 4. Intellect; 5. V olition; 6. Emotion, Religion, and M orality. Ideally, users of the thesaurus should master this system sufficiently well to be able to home in on the words they need. However, like subsequent editors, R oget was realist enough to appreciate that not all users would have the capacity or commitment to do this, and added an alphabetical index. It is often a sorrow for thesaurus-makers, and an argument against the universality of human conceptual structures, that one person's self-evident system of classification will be largely mysterious to others.

W ithin the overall structure, Roget offers a flat classification of 1000 categories, subdivided by part of speech, usually with further subdivisions on semantic grounds. Each division or subdivision has a headword of general meaning, followed by lists of what may, by a very generous definition, be regarded as synonyms, but may also include hyponyms, meronyms, and members of the same lexical field. (on these and other sense relations see M urphy, this volume, especially 33.3 and 33.4). A s far as possible, the following category contains words of opposite meaning ("correlative terms" - the term antonym was not yet in use), though the practice of laying out the thesaurus in parallel antonymic columns was abandoned from the 1962 edition (D utch 1962). Roget shows himself well aware of some of problems users and critics may have with his work. He acknowledges the impossibility of completely substitutable synonyms, and, no doubt with experience of synonym dictionaries in mind, the equal impossibility of investigating all the "distinctions to be drawn between words apparently synonymous", intending instead 
to "classify and arrange them according to the sense in which they are now used, and which I presume to be already known to the reader" (Davidson 2002: xxvii). Such an assumption has, of course, led to unfortunate results when users have indulged in illinformed substitution.

\subsection{After Roget}

One sure sign that a product has arrived is when a trade or personal name achieves the status of a common noun, as in "Have you got my Roget?". Recognition of the merit of the work was not, how ever, instantaneous. Emblen has some interesting examples of early reviews, and writes: "M ost journals and papers that reviewed the Thesaurus were reservedly complimentary and somewhat bewildered as to how one would use the thing" (1970: 272). N evertheless, the popularity of the book grew, and after the crossword puzzle boom hit N orth A merica and B ritain in the 1920 s, it became an indispensable part of any library (E mblen 1970: 278, 281).

A merican editions of Roget appeared from 1854, with Thomas Y . Crowell and Company taking over as publisher in 1886 and subsequently producing new editions under the title of Roget's International Thesaurus (Emblen 1970: 282). There was some tweaking of Roget's scheme of classification, for example in Chapman's classification into fifteen main categories in the fifth edition, on the grounds that Roget's scheme "... does not coincide with the way most people now apprehend the universe" (Roget's International Thesaurus 1992; quoted in Fischer 2004: 43; see also Hüllen 2009a: 44). A French edition appeared in 1859 with Roget's approval (Hüllen 2009b: 76; K endall 208: 266), and there have been versions in German and other European languages (Hüllen 2009b: 60). 
From time to time, brave souls make a break for freedom and offer al ternatives to Roget's structure, often by choosing a different starting point and reorganising the major classes. Two such were Franz Dornseiff's D er deutsche Wortschatz nach Sachgruppen (1933), and Rudolph Hallig and W alther von W artburg's Begriffssystem als G rundlage für die L exikographie (1952). Dornseiff's classification of German has twenty major classes, beginning with the Inorganic W orld, followed by Plants, A nimals, and Humans, while Hallig and von W artburg have ten classes in three broad groups: The U niverse, $M$ an, and $M$ an and the U niverse (Fischer 2004). It should be noted that theirs is a classification of concepts (in French) rather than a classification of the lexicon of a language like D ornseiff or R oget; theoretically, it could be used to display the lexicon of any language. A ccording to Ullman, the scheme caused a good deal of interest when it was presented at the Seventh International Congress of Linguists in 1952, where it was seen mainly as a framework for displaying and comparing different languages or historical periods (1957: 314-5; see also Hüllen 1999: 18-21). There is no record of its being used in its totality or of having much effect on actual thesaurus-making.

A more practical approach is taken in Tom M CA rthur's Longman Lexicon of Contemporary English (1981), the macrostructure of which is outlined in 24.2 .1 above. This work, which later influenced the database of the UCREL Semantic A nnotation System (USA S), was particularly designed for foreign learners, given the logical use of a thesaurus structure for the learning of vocabulary, and began the later trend for corpus-driven and usage-sensitive learner's thesauruses.

The final set of modern thesauruses which break away from Roget are the historical thesauruses TOE and HTOED, described in 24.3.1 above. These originate 
primarily from the work of Professor M ichael Samuels, who set up the Historical Thesaurus of English project at the University of Glasgow in the 1960s.

\subsection{The Way Ahead}

No lexicographical field is immune to the disruptive effects of new technology, and this is perhaps most true in the field of thesauruses. The distinction above between a synonym dictionary and a thematic-semantic thesaurus is one which breaks down immediately on entering the electronic arena. A synonym dictionary, which reproduces under given headwords a subset of terms in a semantic thesaurus's microstructure, is only necessary in a printed form; an el ectronic equival ent would simply be a thesaurus database which dynamically provides to a user a semantic field based on the original search word.

Extending this line of thought, in a time of instant database search results the sole advantage of al phabetical order is entirely lost, and its disadvantages dominate; it places unrelated items next to each other, it loses the opportunity to make connections useful to a user, and it prohibits easy browsing on one particular subject due to its layout. Dictionary data, laid out in a thesaurus structure, becomes the most attractive hybrid, rather than the converse as now. When scholarship and reference works in the digital age require not isolation and fragmentation, but rather union and seamless integration to best serve a user's needs, the strictures of the al phabet become hindrances rather than advantages, and relics of a printed form which is in decline. W ithout too much hyperbole, it can be easily predicted that the thesaurus, the oldest form of lexicography and one dominant for centuries before the printing revolution, could again become the most dominant form of arrangement in the post-print digital future. 


\section{R eferences}

\section{Dictionaries}

A Dictionary of Selected Synonyms in the Principal Indo-European Languages (1988 [1949]). Ed. Carl Darling Buck. Chicago and London: University of Chicago Press.

A Table Alphabeticall, Conteyning and Teaching the True Writing, and Understanding of Hard U suall English Words (1997 [1604]). By Robert Cawdrey. Ed. Raymond E. Siemens, Toronto: University of Toronto Library.

Begriffssystem als Grundlage für die Lexikographie: Versuch eines Ordnungsschemas (1952). B y Rudol ph Hallig and W alther von W artburg. B erlin: A kademie-V erlag.

Der deutsche Wortschatz nach Sachgruppen (2004 [1933]). By Franz Dornseiff. B erlin and New Y ork: de Gruyter,

An Essay towards a Real Character, and a Philosophical Language (1968 [1668]). By J ohn W ilkins. M enston: Scolar Press.

Historical Thesaurus of the Oxford English Dictionary (2009). Ed. Christian K ay, J ane R oberts, M ichael Samuels, and Irené W otherspoon. Oxford: Oxford University Press.

The Longman Lexicon of Contemporary English (1981). Ed. Tom M CA rthur. Harlow: Longman.

The 0 xford English Dictionary (1884-1928). Ed. Sir J ames A. H. M urray, Henry B radley, Sir William A. Craigie and Charles T. O nions. Supplement and Bibliography (1933). Supplement (1972-1986); ed. Robert W . Burchfield. 2nd. ed., (1989); ed. J ohn A. Simpson and Edmund S. C. W einer. Additions Series, (19937); ed. J ohn A. Simpson, Edmund S. C. W einer and M ichael Proffitt. 3rd. ed. (in progress) OED O nline (M arch 2000-), ed. J ohn A. Simpson, www.oed.com [= OED ]. Oxford: Oxford University Press.

The 0 xford Learner's Thesaurus (2008). Ed. Diana Lea. Oxford: Oxford University Press.

Roget's International Thesaurus, 5th ed.(1992). Ed. Robert L. Chapman. N ew Y ork: HarperCollins.

Roget's Thesaurus of English Words and Phrases. (1962 [1852]). Ed. Robert A . Dutch. Harlow: Longman.

Roget's Thesaurus of English Words and Phrases: 150th anniversary edition (2002 [1852]). Ed. George W. Davidson. London: Penguin. (check refs.)

The Scots Thesaurus (1990). Ed. Iseabail M acleod with Pauline Cairns, Caroline $M$ acafee, and Ruth $M$ artin. A berdeen: A berdeen University Press.

A Shakespeare Thesaurus (1993). Ed. M arvin Spevack. Hildesheim, Zurich, and New Y ork: Olms.

A Thesaurus of OId English (1995). Ed. J ane R oberts and Christian K ay with Lynne Grundy. L ondon: King's College. 2nd ed., 2000. A msterdam: Rodopi.

The Wordtree (1984). Ed. Henry G. Burger. M erriam, K ansas: W ordtree.

Thesaurus of Traditional English M etaphors, 2nd ed. (2002). Ed. P. R. Wilkinson. London and $\mathrm{N}$ ew $\mathrm{Y}$ ork: Routledge.

\section{Secondary sources}


A lexander, $M$ arc and A ndrew Struan (forthcoming, 2013). "'In countries so unciviliz' $d$ as those?' : N otions of Civility in the B ritish Experience of the W orld", in $\mathrm{M}$ artin $\mathrm{Farr}$ and $\mathrm{X}$ avier Guégan (eds.) Experiencing Imperialism. London: Palgrave M acmillan.

Emblen, D. L. (1970). Peter M ark Roget, The Word and the M an. London: Longman.

Fischer, A ndreas (2004). 'The notional structure of thesauruses', in Christian J. Kay and J eremy J. Smith (eds), Categorization in the History of English. A msterdam and Philadelphia: B enjamins, 41-58.

Haartman, R. R. K. and James, Gregory (1998). Dictionary of Lexicography. London: Routledge.

Hüllen, W erner (1999). English Dictionaries 800-1700. The Topical Tradition. Oxford: Clarendon Press.

Hüllen, W erner (2004). A H istory of Roget's Thesaurus: Origins, development, and design. Oxford: Oxford University Press.

Hüllen, W erner (2009a). 'Dictionaries of Synonyms and Thesauruses', in A . P. Cowie (ed.), The Oxford History of English Lexicography, vol. II: Specialized Dictionaries. Oxford: Clarendon Press, 25-46.

Hüllen, W erner (2009b). Networks and K nowledge in Roget's Thesaurus from ancient to medieval. Oxford: Oxford University Press.

Kay, Christian (2010). 'Classification: Principles and Practice', in M ichael A dams (ed.), C unning Passages, C ontrived Corridors: U nexpected essays in the history of lexicography. M onza: Polimetrica, 255-270.

Kay, Christian (2012). 'The Historical Thesaurus of the OED as a R esearch Tool', in K athryn A llan and J ustyna Robinson (eds), C urrent $M$ ethods in H istorical Semantics. B erlin: M outon de Gruyter, 41-58.

Kay, Christian (forthcoming). 'Some Interesting Sounds in the H istorical Thesaurus of the 0 xford English Dictionary'. SE LIM proceedings. Convergent A pproaches to $M$ ediaeval English Language and Literature.

K endall, J oshua (2008). The M an who made Lists: Love, death, madness, and the creation of Roget's Thesaurus. N ew Y ork: G. P. Putnam's Sons.

M cA rthur, Tom (1986). Worlds of Reference. Cambridge: Cambridge U niversity Press.

M cA rthur, Tom (1998). Living Words: Language, lexicography and the knowledge revolution. Exeter: University of Exeter Press.

O'Hare, Cerwyss (2004). "Folk Classification in the HTE Plants Category", in Christian J. K ay and J eremy J. Smith (eds), Categorization in the History of English. A msterdam and Philadel phia: Benjamins, 179-191.

Ullmann, Stephen (1957). The P rinciples of Semantics, 2nd ed. Oxford: B asil Blackwell.

Ullmann, Stephen (1962). Semantics: An introduction to the science of meaning. Oxford: Basil Blackwell.

W ild, K ate (2010). 'A ngel ets, Trudgeons, and B ratlings: The lexicalization of childhood in the Historical Thesaurus of the Oxford English Dictionary', in $M$ ichael A dams (ed.), Cunning Passages, C ontrived Corridors: U nexpected essays in the history of lexicography. M onza: Polimetrica, 290-308.

\footnotetext{
' For a discussion of the issues involved in classifying plants, see $\mathrm{O}^{\prime} \mathrm{H}$ are (2004). Further details about HTOED can be found in its Introduction and in Kay (2010; 2012).
} 


\footnotetext{
ii We are indebted to A ndrew B all of the OED for this example.

iii This section draws heavily on Hüllen (1999), to which the reader is referred for a much more detailed account of the early history of thesauruses.

iv A full description and analysis is given in Hüllen (1999), chapter 8.
} 